\title{
Article \\ The Bright Side of the Tiger: Autofluorescence Patterns in Aedes albopictus (Diptera, Culicidae) Male and Female Mosquitoes
}

\author{
Anna C. Croce $1,2, *$ (D) and Francesca Scolari $1,2, *$ (D) \\ 1 Institute of Molecular Genetics, Italian National Research Council (CNR), Via Abbiategrasso 207, \\ 27100 Pavia, Italy \\ 2 Department of Biology \& Biotechnology, University of Pavia, Via Ferrata 9, I-27100 Pavia, Italy \\ * Correspondence: croce@igm.cnr.it (A.C.C.); francesca.scolari@igm.cnr.it (F.S.); Tel.: +39-0382-986428 (A.C.C.); \\ +39-0382-986421 (F.S.)
}

Citation: Croce, A.C.; Scolari, F. The Bright Side of the Tiger:

Autofluorescence Patterns in Aedes

albopictus (Diptera, Culicidae) Male and Female Mosquitoes. Molecules 2022, 27, 713. https://doi.org/ $10.3390 /$ molecules 27030713

Academic Editor: Fernando Baiao Dias

Received: 16 December 2021

Accepted: 20 January 2022

Published: 21 January 2022

Publisher's Note: MDPI stays neutral with regard to jurisdictional claims in published maps and institutional affiliations.

Copyright: (C) 2022 by the authors. Licensee MDPI, Basel, Switzerland. This article is an open access article distributed under the terms and conditions of the Creative Commons Attribution (CC BY) license (https:// creativecommons.org/licenses/by/ $4.0 /)$.

\begin{abstract}
Light-based events in insects deserve increasing attention for various reasons. Besides their roles in inter- and intra-specific visual communication, with biological, ecological and taxonomical implications, optical properties are also promising tools for the monitoring of insect pests and disease vectors. Among these is the Asian tiger mosquito, Aedes albopictus, a global arbovirus vector. Here we have focused on the autofluorescence characterization of Ae. albopictus adults using a combined imaging and spectrofluorometric approach. Imaging has evidenced that autofluorescence rises from specific body compartments, such as the head appendages, and the abdominal and leg scales. Spectrofluorometry has demonstrated that emission consists of a main band in the $410-600 \mathrm{~nm}$ region. The changes in the maximum peak position, between $430 \mathrm{~nm}$ and $500 \mathrm{~nm}$, and in the spectral width, dependent on the target structure, indicate the presence, at variable degrees, of different fluorophores, likely resilin, chitin and melanins. The aim of this work has been to provide initial evidence on the so far largely unexplored autofluorescence of Ae. albopictus, to furnish new perspectives for the set-up of species- and sex-specific investigation of biological functions as well as of strategies for in-flight direct detection and surveillance of mosquito vectors.
\end{abstract}

Keywords: resilin; chitin; melanin; antennae; maxillary palps; scales; imaging; spectrofluorometry; sexual dimorphism

\section{Introduction}

Autofluorescence (AF) emission in the near-UV-visible/near-IR spectral range can occur in all living organisms when irradiated with proper excitation light, depending on the presence of endogenous biomolecules with suitable chemical properties [1]. These include conjugated double bonds, aromatic, oxidized and crosslinked complex structures, with molecular energy conditions allowing electronic transitions matching with light absorption and emission. Early observations on autofluorescence from different biological substrates have paved the way to constant and innumerable studies entailing light based phenomena. Indeed, the direct involvement of endogenous fluorophores in the structure and metabolic functions of cells and tissues, causing them to act as intrinsic biomarkers, is at the basis of the development of diagnostic strategies in biomedicine, as well as of various industrial and analytical procedures with almost countless applications in many areas, from microorganisms to vegetables or animals [2].

Interest is increasingly addressed to light-based events in Arthropoda, and their various consequences [3]. The biological and ecological roles of light-based events have been related to inter- and intra-specific visual communication, including species recognition, mate finding, prey detection, camouflage and agonistic behavior [3,4]. On the other hand, insect optical properties have been suggested as a tool to sensitively monitor the presence 
of pest larvae in stored food or during processing [5], to detect infestations early [6], or to differentiate in situ mosquito species and sex to improve vector surveillance [7].

In this context, the fluorescence emission properties of members of this phylum of the animal kingdom are still a poorly investigated area, not only from the chemical point of view but also in terms of the photo-physical and biological aspects. Besides the characterization of the fluorescing pigments in Lepidoptera [8], and of the photonic effects of butterfly scales [9-11] or of the thorax and elytra cuticle in beetles [12], interest has been devoted to fluorescing components playing a functional role in mechanically active tissues. Several studies have focused on the bluish fluorescing resilin, a protein described as rubber-like due to its distinctive elastic mechanical properties, endowed by its chemical composition. In combination with other proteins or with the sclerotized or chitinous cuticle, fluorescing in the green and red spectral regions, respectively, resilin allows the accomplishment of a variety of mechanical and receptor functions [13-15]. In this regard, the particular ability of the antennae to play various sensory roles in detecting chemicals, as well as sound vibrations, can account for the frequent occurrence of speciesand sex-specific structural variability entailing differences in the compositional material, responding to the adaptation to the different needs of mosquitoes [16,17]. For example, the in situ analysis of both mosquito and midge antennae AF highlighted the importance of the compositional material in modulating the mechanical response to vibrations, with perspectives for the set-up of sound or vibration biomimetic sensor detectors [16,17]. On the other hand, a sophisticated characterization of the optical properties of the entire body of some mosquitoes, in terms of scattering properties investigated using a multispectral and polarimetric setup, has provided promising perspectives for the species-specific detection of in-flight mosquitoes for entomological purposes and the direct surveillance of malaria vectors [7]. Although these reports suggest that natural fluorescence has an important role in insect studies, this phenomenon is still poorly investigated, especially in mosquitoes.

The Asian tiger mosquito, Aedes albopictus (Skuse, 1894) (Diptera, Culicidae), is an aggressive day-light biter competent for at least 20 arboviruses, including chikungunya, Zika and dengue viruses [18-24]. This species is a global invader because of its life history traits and the high, human-driven, propagule pressure [25]. In the absence of effective vaccines against the pathogens vectored by Ae. albopictus, the control of mosquito populations is essential to limit the burden of diseases. Expanding knowledge on the AF patterns of Ae.albopictus tissues is of relevance not only to acquire a deeper knowledge of these phenomena in the frame of the biology of the species, but also to devise innovative applications for in situ surveillance of mosquito vectors, as suggested for Anopheles species [7]. Currently, optical data on Ae. albopictus are practically limited to a study on the whole-body reflectance properties, which were shown to be sensitive to background colors when these mosquitoes were used as models to investigate technologies for light-based proximal remote sensing for the classification of biological and engineering objects [26].

The aim of this study was to: (i) describe, for the first time, the AF properties of Ae. albopictus adults; (ii) assess possible AF differences in sexually dimorphic traits. Mosquitoes are indeed ideal targets to explore sexual dimorphism since males and females display different behaviors enabled by specific body structures, also important for their role as pathogen vectors. Hence, particular attention has been devoted to the antennae and maxillary palps, as sexually dimorphic head appendages with key sensory roles. Moreover, we focused on abdominal and leg scales, which are common to both sexes and contribute to the typical striped pattern of the Asian tiger mosquito. The AF of these structures has been characterized by means of microscope AF imaging, to provide directly and in a label-free manner the topological distribution of the emission signal, and a microspectrofluorometric approach, expected to indicate the presence of differently fluorescing biomolecules. The results of this study provide interesting perspectives for the application of AF-based procedures to novel species- and/or sex-specific methods for mosquito control in the field. 


\section{Results}

2.1. Autofluorescence in the Head Appendages of Male and Female Ae. albopictus Adults

Observations of Ae. albopictus male and female adult heads under bright field microscope conditions allow the appreciation of the marked morphological differences in the antennae and maxillary palps (Figures $1 \mathrm{~A}$ and $2 \mathrm{~A}$ ) related to sexual dimorphism in mating and feeding behaviors [27].
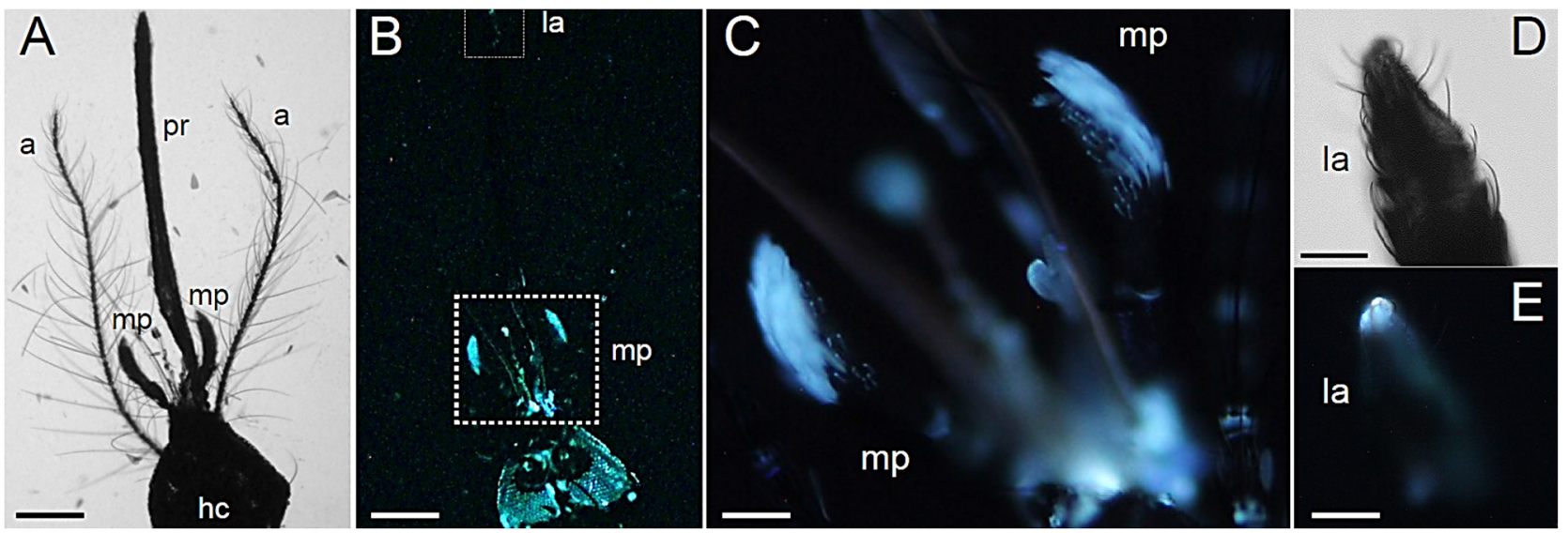

Figure 1. Head structures in Ae. albopictus adult females. (A) Bright field light view of the dorsal female head showing proboscis (pr), maxillary palps ( $\mathrm{mp}$ ) and antennae (a) departing from the head capsule (hc). (B) Fluorescent light view of the dorsal female head. Labella (la). (C) Fluorescent light view of the maxillary palps (mp). Bright field (D) and fluorescent (E) light view of the labella. Bars: $250 \mu \mathrm{m}(\mathbf{A}, \mathbf{B}) ; 60 \mu \mathrm{m}(\mathbf{C}) ; 30 \mu \mathrm{m}(\mathbf{D}, \mathbf{E})$.
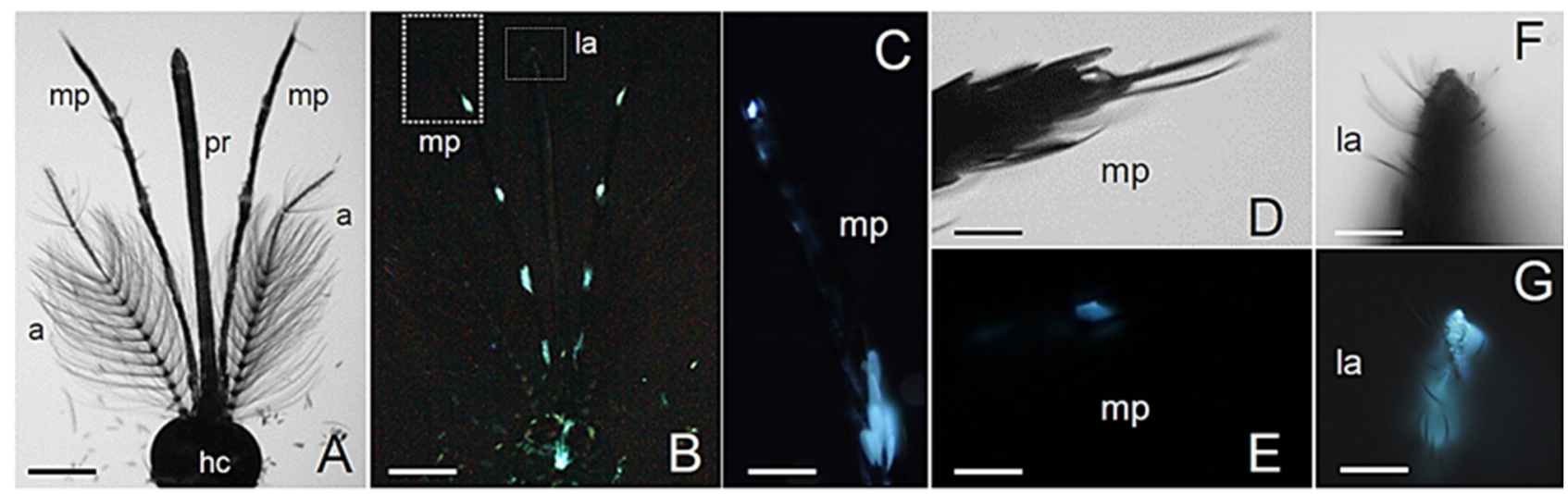

Figure 2. Head structures in Ae. albopictus adult males. (A) Bright field light view of the dorsal male head showing proboscis ( $\mathrm{pr}$ ), maxillary palps ( $\mathrm{mp}$ ) and antennae (a) departing from the head capsule (hc). (B) Fluorescent light view of the dorsal male head. Labella (la). (C) Fluorescent light view of the distal portion of a maxillary palp. Bright field (D) and fluorescent (E) light view of the terminus of a maxillary palp. Bright field (F) and fluorescent (G) light view of the labella. Bars: $360 \mu \mathrm{m}(\mathbf{A}, \mathbf{B})$; $90 \mu \mathrm{m}(\mathbf{C}) ; 25 \mu \mathrm{m}(\mathbf{D}, \mathbf{E}) ; 40 \mu \mathrm{m}(\mathbf{F}, \mathbf{G})$.

Differences emerge also in terms of AF patterns, which evidence regions with strong bluish emission (Figures 1 and 2).

In both sexes, fluorescence arises from the antennae, the maxillary palps and the labella (Figures 1B and 2B). In the female, the silvery-white scales present in the apex of palpomere 4 [28] display a strong bluish emission (Figure 1B,C), similarly to the very tip of the proboscis (Figure 1D,E). In the male, the maxillary palps are longer than in the female and show a strong AF in correspondence to the silvery-white scale bands located at the base of palpomeres 2 to 5 [29] (Figure 2B,C) and in the terminus of the maxillary palp 
(Figure 2D,E). Similar to what is observed in the female, blue emission is detectable in the very tip of the proboscis (Figure 2F,G), which is dark scaled [29].

When focusing on the antenna, which in both sexes consists of thirteen flagellar segments, called flagellomers [30], a sex-related pattern of fluorescence is evident both at the flagellomer joints and in the sensilla (Figures 3 and 4). As to the flagellomer joints, in the female two different regions appear to be fluorescent: a thin disc and a larger cone, where sensilla chaetica arise from their sockets (Figure 3).

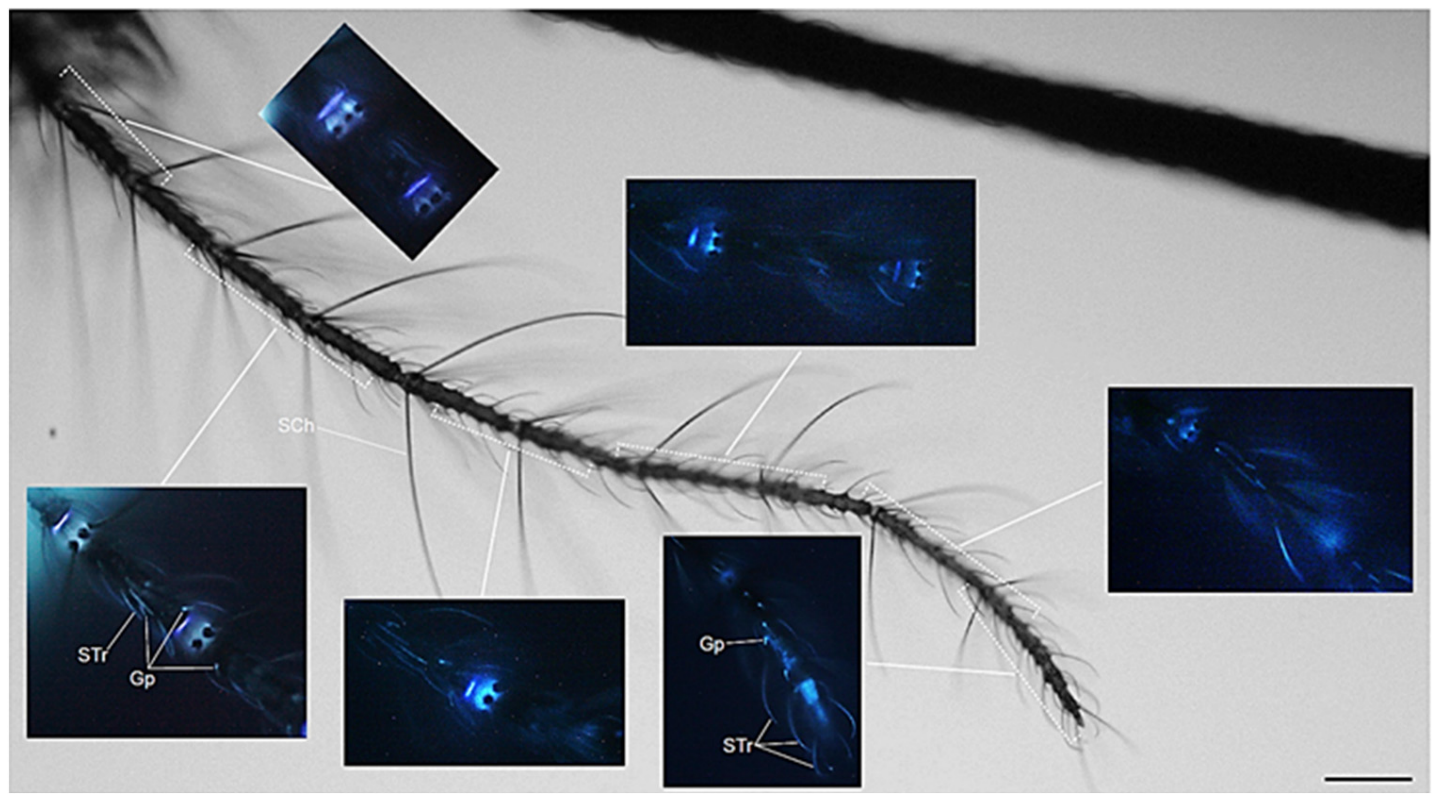

Figure 3. Ae. albopictus adult female antenna. Bright field light view of the antenna, with inserts showing the AF in the flagellomer joints and in the sensilla. Sensilla chaetica (SCh); sensilla trichoidea (STr); short grooved peg (Gp) sensilla. Bar: $100 \mu \mathrm{m}$.

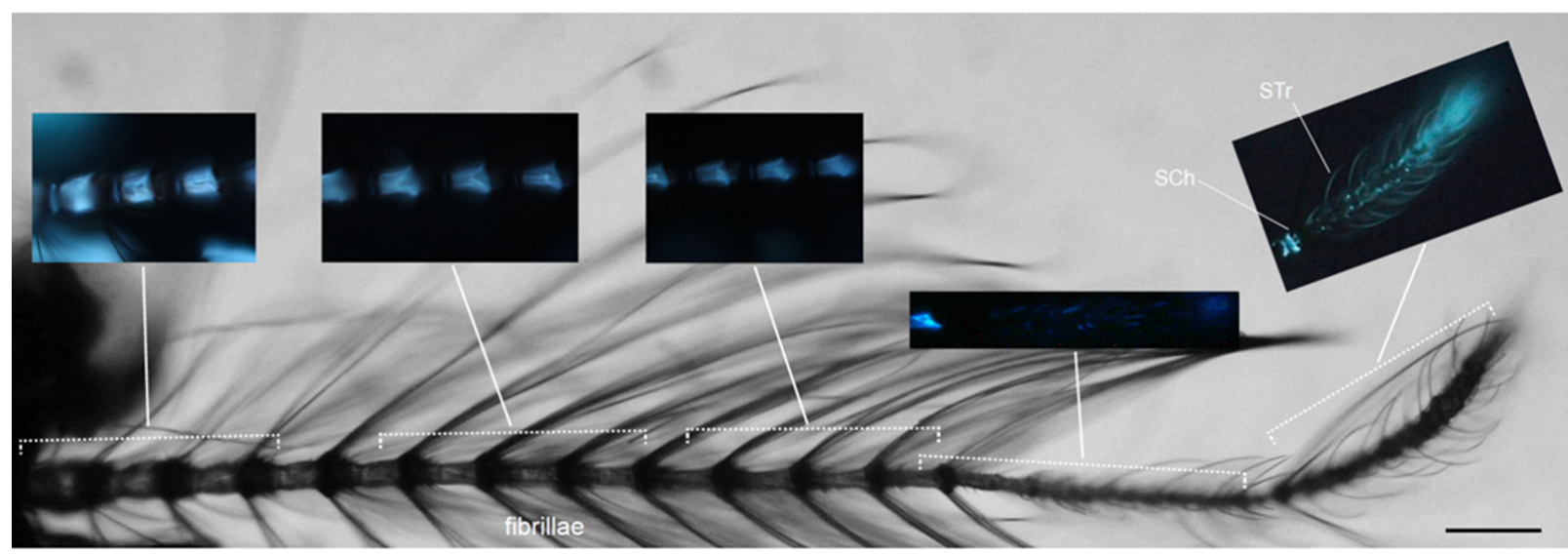

Figure 4. Ae. albopictus adult male antenna. Bright field light view of the antenna with inserts showing the AF in flagellomers 1 to 11 and in the sensilla, especially those located on the terminal flagellomer. Sensilla chaetica (SCh) arising from their sockets; sensilla trichoidea (STr). Bar: $100 \mu \mathrm{m}$.

In the male, flagellomers 1 to 11 bear long fibrillae that are organized in a complex with the scolophores of the Johnston's organ and are involved in hearing [30]. These eleven flagellomers are intensely fluorescent, with a blue disc distinguishable at the joints (Figure 4).

Antennal sensilla are distributed along the entire length of the female antenna and the two terminal segments in the male. 
In the female, non-fluorescent sensilla chaetica insert in the flagellomer joint cones and are organized in a whorl at the base of each of flagellomers 2-13 (Figure 3). Along the flagellomers, fluorescence is visible in the sensilla trichoidea-hair-like structures distributed on each segment of the antennal flagella, where they are the primary olfactory sensilla-and in the short-grooved peg (Gp) sensilla (Figure 3).

In the male, non-fluorescent sensilla chaetica are located in whorls at the base of the terminal flagellomer, whereas the subterminal segment carries fibrillae at the base and sensilla chaetica along the shaft (Figure 4). The terminal segment shows strong fluorescence not only at the terminus, where campaniform organs are located, but also in several sensilla. In this respect, it is important to recall that short sensilla basiconica and sensilla trichodea (both long and short) are known to be distributed along the terminal flagellomer [30].

\subsection{Autofluorescence in Ae. albopictus Body Scales}

Males and females display a similar AF pattern in the organization of the scales covering the abdomen, both dorsally (tergites) and ventrally (sternites) (Figures 5 and 6). Notably, the AF patches of the mosquito abdomen correspond to the white bands typical of the Asian tiger mosquito striped pattern [31]. These white scales exhibit a remarkable AF emission, either bluish or reddish, apparently depending on their localization in the tergites (Figures 5B,C and 6B,D), as well as in the sternites (Figures 5E and 6F,H).

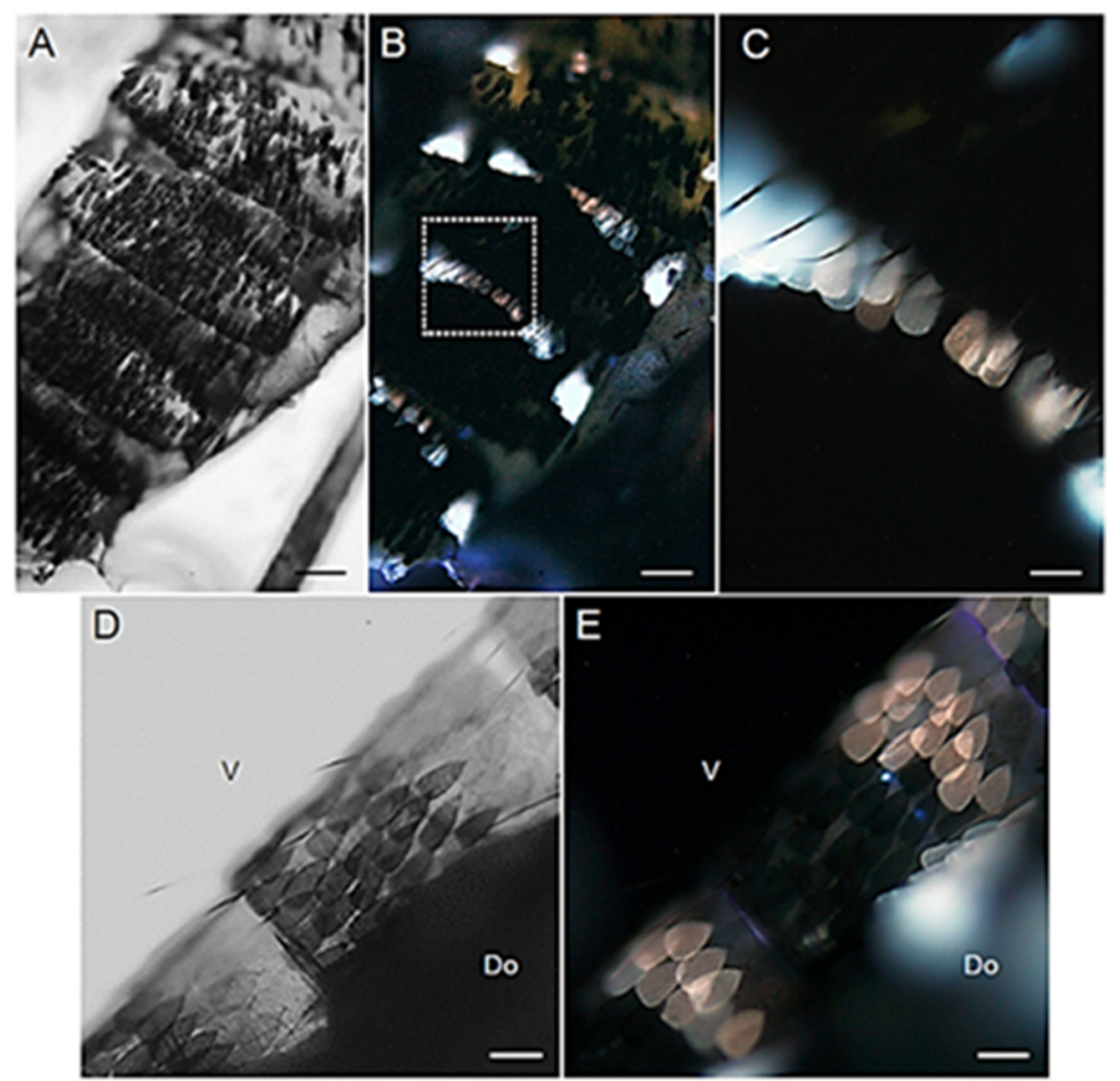

Figure 5. Abdominal scales in adult Ae. albopictus females. (A) Bright field and (B) AF view of dorsal abdominal segments. (C) Enlarged view of the dorsal abdominal scales indicated by the dashed box in (B). (D) Bright field and (E) AF view of a portion of the ventral sternites with scales. Ventral (V) and dorsal (Do) sides. Scale bars: $110 \mu \mathrm{m}(\mathbf{A}, \mathbf{B}) ; 20 \mu \mathrm{m}(\mathbf{C}-\mathbf{E})$. 

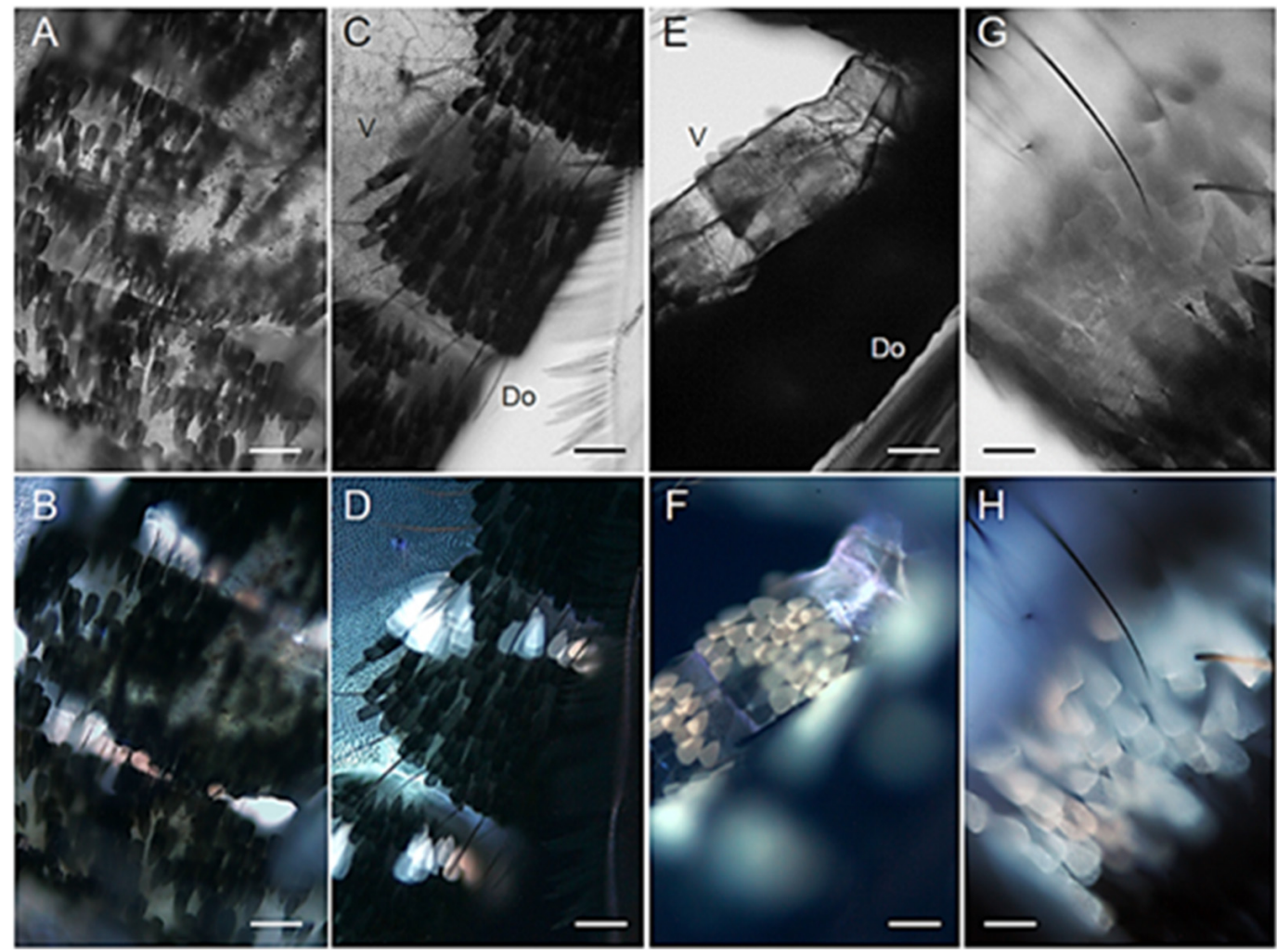

Figure 6. Abdominal scales in adult Ae. albopictus males. (A) Bright field and (B) AF view of dorsal abdominal segments. (C) Bright field and (D) AF lateral view of dorsal abdominal segments. (E) Bright field and (F) AF view of a portion of the ventral sternites with scales. (G) Bright field and (H) AF enlarged view of ventral abdominal scales. Ventral (V) and dorsal (Do) sides. Scale bars: $50 \mu \mathrm{m}(\mathbf{A}-\mathbf{D}) ; 60 \mu \mathrm{m}(\mathbf{E}, \mathbf{F}) ; 30 \mu \mathrm{m}(\mathbf{G}, \mathbf{H})$.

Considering the strong AF emission of the abdominal white scales, we also particularly focused on the observation of the hindleg tarsi, because of the abundance and size of their white bands. Indeed, the hindleg tarsi display basal white bands on tarsomeres 1-4 and an entirely white tarsomere 5 [31]. As expected, such white rings display a strong bluish AF without appreciable differences between the sexes (Figures 7 and 8).
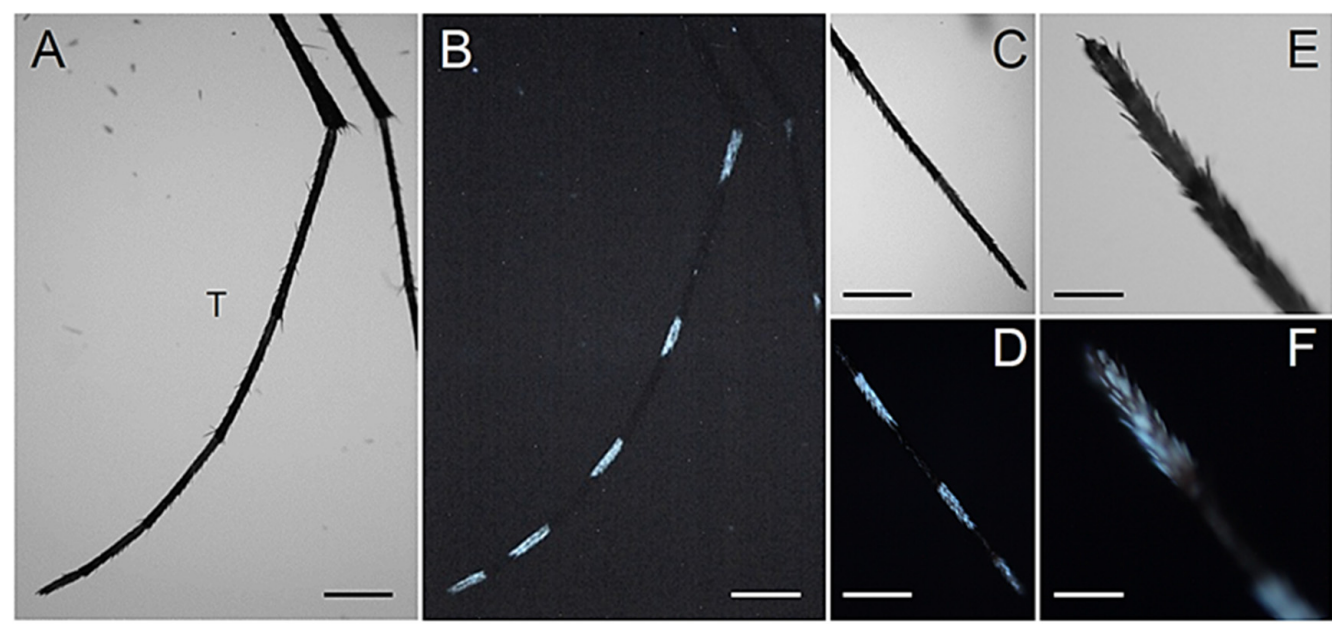

Figure 7. Hindleg tarsal scales in adult Ae. albopictus females. (A) Bright field and (B) AF view of a hindleg tarsus (T). (C) Bright field and (D) AF view of the third, fourth and fifth basal bands. (E) Bright field and (F) AF enlarged view of the fifth tarsomere. Scale bars: $400 \mu \mathrm{m}(\mathbf{A}, \mathbf{B}) ; 300 \mu \mathrm{m}$ (C,D); $80 \mu \mathrm{m}(\mathbf{E}, \mathbf{F})$. 


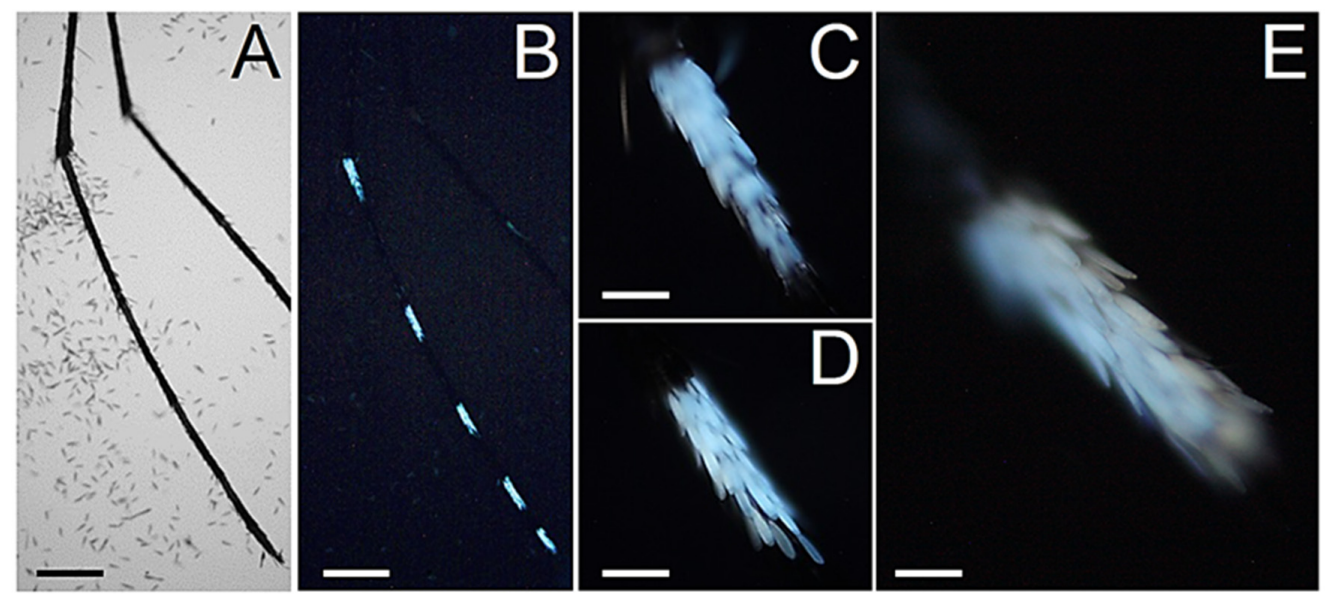

Figure 8. Hindleg tarsal scales in adult Ae. albopictus males. (A) Bright field and (B) AF view of a hindleg tarsus (T). (C) AF view of the fluorescent scales of tarsomere 1. (D) AF view of the fluorescent scales of tarsomere 3. (E) Enlarged view of tarsomere 5. Scale bars: $400 \mu \mathrm{m}(\mathbf{A}, \mathbf{B}) ; 60 \mu \mathrm{m}(\mathbf{C}, \mathbf{D})$; $30 \mu \mathrm{m}(\mathbf{E})$.

\subsection{Spectrofluorometric Analysis}

Spectrofluorometric analysis of the different fluorescing structures of Ae. albopictus adult bodies revealed by AF imaging indicates that emission commonly consists in a main band in the 410-600 nm spectral interval (maximum peaks ranging between $480 \mathrm{~nm}$ and $455 \mathrm{~nm}$ ). Obviously, dark areas do not show appreciable signals.

Depending on the sex and on the structure observed, spectral profiles can exhibit some differences. In the female, labella spectra show a slight widening towards longer wavelengths as compared with the male (Figure 9A), whereas the profiles of the spectra from the bluish emitting areas of the maxillary palps are very similar in the two sexes (Figure 9B). In the antennae, comparable spectral shapes are detected between the male flagellomers and the blue disc joints of the female flagellomers. The signal from the conical structures in the female flagellomer joints is instead shifted toward longer wavelengths by more than $25 \mathrm{~nm}$, with a peak position at about $480 \mathrm{~nm}$ as compared with the peak at about $453 \mathrm{~nm}$ of the shorter emitting structures (Figure 9C).

Differences in spectral profiles also occur in AF emission from the scales of the abdomen.

Spectra recorded from the bluish scales of the male show a slight widening towards longer wavelengths in the 520-600 $\mathrm{nm}$ region in ventral as compared with dorsal scales; a similar change is observed for the spectra recorded in the female (Figure 9D). When emission spectra from bluish and reddish scales are compared, the latter show a marked widening of the spectrum towards the red region, even indicating a minor shoulder in the 520-600 nm region (Figure 9E). Finally, the fluorescing scales of the hindleg tarsi do not show remarkable differences between females and males (Figure 9F).

The parameter data characterizing the shape of the spectra shown in Figure 9 are summarized in Table 1, along with data from spectra recorded from the fore trochanterfemur joint and from the maxilla, structures commonly known to be specifically enriched in resilin and sclerotized chitin, respectively [32,33] (Figure S1). 

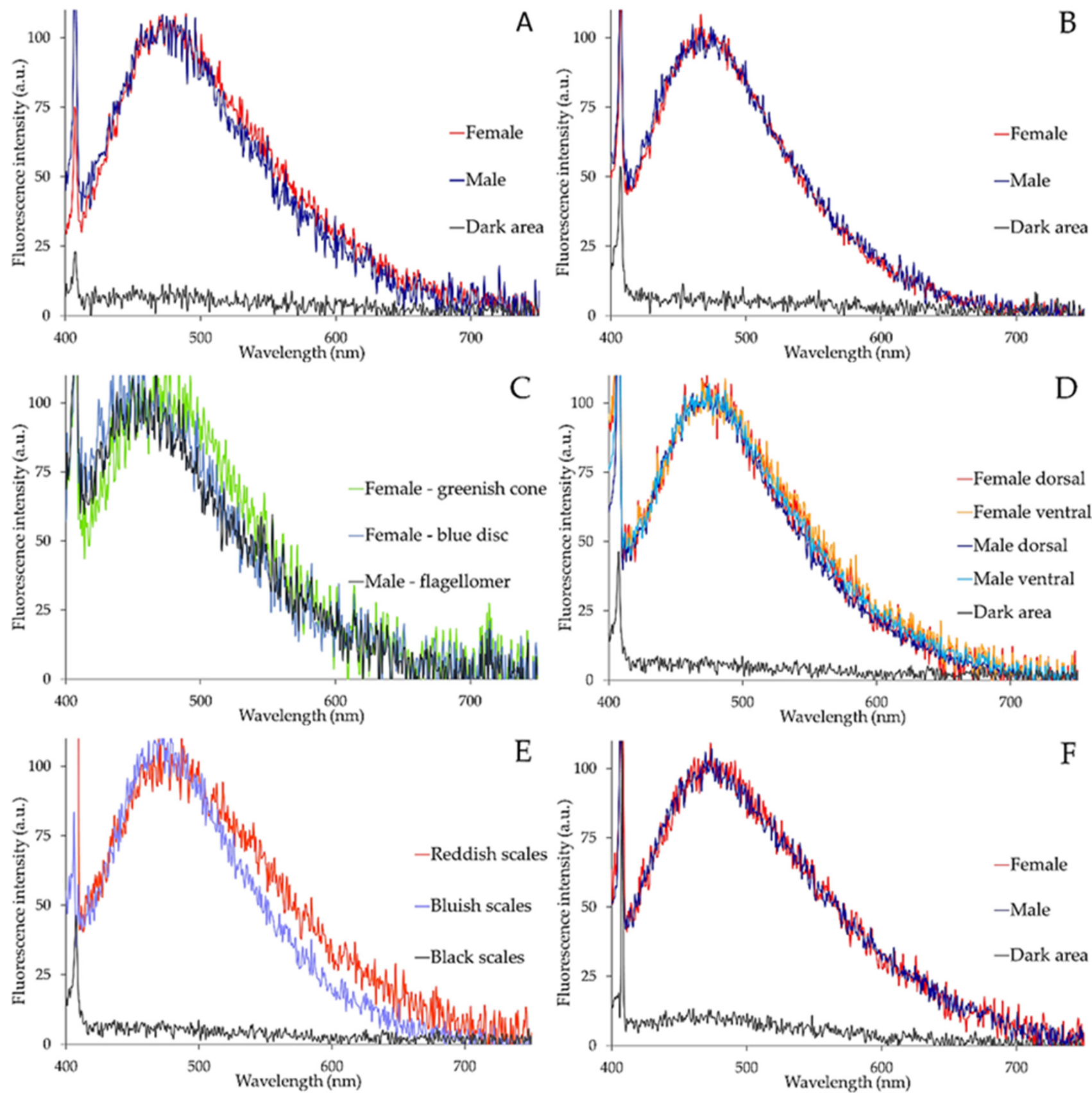

Figure 9. Typical examples of the AF spectra recorded from labella (A), maxillary palps (B), antennal elements $(\mathbf{C})$, abdominal scales (D,E) and hindleg tarsi (F) of Ae. albopictus adult females and males. Spectra are normalized to the maximum peak intensity $(100 \%)$ to better compare emission profiles. Spectra from females or males, or from selected structures, are identified by colors, as reported in the inlet legend on the right. 
Table 1. Peak position and Full Width at Half Intensity Maximum (FWHM) of spectra from Ae. albopictus fluorescing structures.

\begin{tabular}{ccc}
\hline Structure & Peak Maximum * & FWHM * \\
\hline Labella & $470-480 \mathrm{~nm}$ & $140-145 \mathrm{~nm}$ \\
\hline Maxillary palps & $460-480 \mathrm{~nm}$ & $120-130 \mathrm{~nm}$ \\
\hline $\begin{array}{c}\text { Antennal elements } \\
\text { Male flagellomer/female blue disc }\end{array}$ & $440-470 \mathrm{~nm}$ & $123-130 \mathrm{~nm}$ \\
Female greenish cone & $460-490 \mathrm{~nm}$ & $132-140 \mathrm{~nm}$ \\
\hline Abdominal scales & & \\
Bluish & $460-490 \mathrm{~nm}$ & $137-145 \mathrm{~nm}$ \\
Reddish & $470-500 \mathrm{~nm}$ & $147-160 \mathrm{~nm}$ \\
\hline Hindleg tarsi & $470-480 \mathrm{~nm}$ & $153-157 \mathrm{~nm}$ \\
\hline Fore trochanter-femur joint & $430-455 \mathrm{~nm}$ & $134 \mathrm{~nm}$ \\
\hline Maxilla & $465-490 \mathrm{~nm}$ & $155 \mathrm{~nm}$ \\
\hline
\end{tabular}

* Peak emission and FWHM may vary depending on the combination between different biomolecules and fluorophores.

\section{Discussion}

Autofluorescence imaging has evidenced that, in general, AF rises from distinct body compartments of the Asian tiger mosquito, Ae. albopictus. Spectral data, in turn, have indicated that emission consists in a major band in the 410-600 nm region, with some changes in maximum peak position and spectral width depending on the structure analyzed. These findings are likely indicating the presence of different fluorophores, as well as changes in the degree of their inter-molecular organization and/or in their possible combinations within mosquito tissues. In this regard, it is commonly known that the AF properties of various structures in arthropods are mostly attributable to proteinaceous components, namely resilin, chitin and melanin. These biomolecules are thus the most likely responsible for the AF signals detected in the body of Ae. albopictus.

In the mosquito head, the bluish AF observed at the antennal nodes in males and females likely reflects an enriched presence of resilin. This suggestion is corroborated by the narrow shape and short wavelength localization of AF spectra, comparable to those recorded from the foreleg trochanter-femur joint, whose richness in resilin is in turn consistent with the recognized common presence of this protein in insect leg joints $[34,35]$. The presence of resilin in Ae. albopictus antennae is also in agreement with previous reports on the antennae of the midge Chironomus riparius, or of the mosquitoes Toxorhynchites brevipalpis and Anopheles arabiensis, and with their functions in sound and vibration detection, with differences in sex- and species-specific morphological and mechanical properties [16,17].

Indeed, the super-elastic properties of resilin are well known to play essential mechanical roles in arthropods, assisting movement and protecting compartments engaged in movement [36-38].

In some mosquito species, resilin is a cuticle structural protein characterized at the genomic, transcriptomic, proteomic and ultrastructural levels $[39,40]$. In Ae. aegypti, the spermathecal duct has been shown to contain resilin, which is responsible for its capacity to stretch [41-44], and this protein has been also suggested to be present in the dorsal wall of the female labrum in different mosquitoes [45]. As to Ae. albopictus, to the extent of our knowledge studies confirming the specific presence of one or more resilin genes and the related functions are not available yet, apart from a preliminary BLAST search of resilin in the Asian tiger mosquito genome that identified potential promising candidates [46].

Our spectral data from Ae. albopictus antennae also evidenced a slight shift towards a longer wavelength in the signal recorded from the cones as compared with the blue discs in the female, indicating a change in resilin molecular organization and/or its mixed coexistence with other compounds, such as chitin. On the other hand, in the antennae of males, flagellomers 1 to 11 are shorter and much richer in the AF signal ascribable to 
resilin, likely to withstand the effort in carrying the numerous fibrillae of multiple lengths. The two terminal segments, on the contrary, appear to be more similar to the female flagellomers, and no remarkable AF signal can be appreciated from their main body, apart from numerous different sensilla along the shaft.

Actually, chitin has been already reported as a component of mosquito antennae [47], and, more generally, of insects, e.g., in coleoptera [48] and in blattodea [49].

Possible changes in the molecular features of resilin, along with the ability of this protein to coexist with chitin and additional compounds such as melanin, are acknowledged to ensure variable mechanical properties and resistance adequate to the functions of different apparatus of arthropods, as well as to the changes in fluorescing signal [13,50-52].

Chitin is a complex biopolymer of sugar products, acting as the structural constituent of extracellular matrices in arthropods, and which is increasingly considered for industrial and pharmaceutical sustainable applications [53,54]. A chemically-purified chitin was shown to fluoresce in the 400-600 nm spectral interval, with the maximum spectral peak at about $440 \mathrm{~nm}$ [55]. On the other hand, in situ image analysis applied to different arthropod species by using couples of excitation and emission filters at increasing wavelengths allowed the identification of areas with prevailing blue, green or red emission, ascribed, respectively, to resilin, to poorly sclerotized chitinous structures or to strongly sclerotized chitinous structures [13,56]. The selective detection of prevailing blue or green AF has been applied for investigations on the functional and evolutionary adaptation of arthropod structures. Examples of such studies include the analysis of the gradient in the mixing between the bluish resilin and greenish chitin accounting for the optimization of adhesive and mechanical properties of the tarsal setae of the second adhesive pad of female forelegs in the ladybird beetle Coccinella septempunctata [57], as well as the identification and functional characterization of antennal gustatory sensilla in the poplar leaf beetle Crysomela populi [15]. In this regard, the above described AF properties suggest a mixed existence of resilin and chitin in the repeated units in Ae. albopictus female antennal flagellum, and a richer presence of resilin in male antennae. These features are relatable to differences in mechanical properties, such as stiffness, relevant to different sensory capabilities. This suggestion is supported by a report on the sex-specific differences in relative antennal bending stiffness and vibration velocities in the two sexes of Ae. aegypti [58] and on the ability of mosquito females to emit sound signals to attract males and participate in bidirectional acoustic interactions $[59,60]$.

In the maxillary palps, our AF spectra peak at slightly longer wavelengths than those from the antennal blue discs in females and flagellomers in males. In Ae. aegypti females, the maxillary palps have been reported to be involved in olfaction as well as mechano- and thermo-sensation. Female host-seeking is indeed known to be activated by the detection of $\mathrm{CO}_{2}$ by the maxillary palps [61], which vibrate during probing and in the first few seconds of blood feeding $[62,63]$. Interestingly, in Ae. aegypti $\mathrm{CO}_{2}$ sensitivity is similar in males and females [64], possibly to favor male nectar seeking [65]. In anopheline, based on the species- and sex-specific transcriptional profiles observed for chemosensory genes, male maxillary palps have been suggested to play a role in mate recognition [66]. On the other hand, up to now the microtrichia and scales covering both male and female maxillary palps in Ae. aegypti have been reported as cuticular structures without sensory functions [63]. Such a lack of sex-specific sensory functions may account for the absence of appreciable differences in AF properties, and thus in biochemical composition, between male and female palp scales in Ae. albopictus. In this context, and considering the morphological and functional dimorphisms between males and females, a role for the Ae. albopictus maxillary palp scales in improving the efficacy in chemical signal perception, already suggested for moths [67], remains an open and interesting question.

The red shift and spectral widening observed for the AF from the maxillary palps as compared with antennal nodes are even more evident in the proboscis labella, two hairy muscular lobes located at the tip of the gutter-like labium [68]. In addition to the labium, the proboscis of female mosquitoes comprises a feeding fascicle of six stylets. These structures, 
namely a larger and central labrum, the flattened hypopharynx with its salivary canal, a pair of long thin mandibles and a pair of needle-like maxillae, belong to the exoskeleton and consist of chitin and variable protein matrices [32]. The red shift characterizing our AF spectra may thus reflect a contribution from the sclerotized chitinous structures of Ae. albopictus proboscis stylets.

Additionally, the spectra recorded from the body scales show a red shift with respect to the bluish structures of the antennae. The change is less evident for the scales of the hindleg tarsi than for the abdomen. This finding can account for a different combination of resilin with other proteinaceous materials, including chitin, whose AF has been previously identified in the scales of moth and butterfly species [69].

Melanins are also likely to contribute to different extents to the AF of Ae. albopictus body scales. The presence of intermediate products of the melanin synthesis pathway has been already confirmed to contribute to the color of wing scales in butterflies [70,71], in addition to a recognized participation in the modulation of a wide range of physiological processes that are conserved across insects, including immunity, wound healing and protection from parasitoids and UV light [72,73]. Melanins are reddish or brown-black heterogeneous biopolymers, respectively termed pheomelanin or eumelanin, derived from the common precursor tyrosine [74]. Both eumelanin and pheomelanin strongly absorb visible light, with a continuous absorption curve decreasing exponentially from the shorter to the longer wavelengths in the visible spectral interval [75-77] and can exhibit distinct AF properties. In particular, synthetic eumelanin in solution at different concentrations has shown an excitation band around $360 \mathrm{~nm}$ when observed at emission wavelengths ranging from 450 to $570 \mathrm{~nm}[76,77]$, whereas a major pheomelanin component, the 6-(2-amino-2-carboxyethyl)4-hydroxy-1,3-benzothiazole derivative, has shown a fluorescence emission spectrum in the 400-600 nm range [78]. This evidence is thus consistent with the contribution of melanins to the reddish components of the AF from the scales of Ae. albopictus. Finally, a possible additional contribution to the AF detected from our mosquito samples might rise from actin, a component that has been demonstrated to be essential for the development of scales, from the cylindrical shape in the pupal stages to the flattened form in the adult in Ae. aegypti [79].

Changes in the AF pattern of Ae. albopictus body scales may be thus ascribed to the presence of different biomolecules, indicating that their synthetic pathways have been adapted to meet specific needs of different insect species. Indeed, scales are known to serve a variety of functions, from species recognition and thermal regulation, to aposematism [80], and phenotypic changes in Ae. aegypti, including scale patterns, have been associated with seasonal variations and larval breeding sites [18,81]. However, the function of scales is still largely unknown in Diptera, including mosquitoes [80]. Despite such a knowledge gap regarding scale structure and function, a valuable practical consequence of the observed variability is that scale features can be exploited for taxonomic studies. The scale color in the Culicidae family has indeed been considered as a key characteristic to distinguish different species [28,82-84], and in Ae. aegypti the variability in abdominal scale color, ranging from white to gold, allows the differentiation of rare morphological mutants and avoids their misinterpretation as new forms or species [85].

\section{Materials and Methods}

\subsection{Insect Samples}

Aedes albopictus eggs were collected using ovitraps in Northern Italy (Seniga, BS, $45^{\circ} 14^{\prime} 35.33^{\prime \prime} \mathrm{N}, 10^{\circ} 10^{\prime} 50.98^{\prime \prime} \mathrm{E}$ ) in August and September 2021. Hatched larvae were reared on fish food pellets (Goldfish Granules, Tetra $\mathrm{GmbH}$, Melle, Germany). Emerging adults were reared in a climatic chamber at $25^{\circ} \mathrm{C}$, with $60-75 \%$ relative humidity and a $12: 12 \mathrm{~h}$ (L:D) photoperiod and maintained on a $20 \%$ sugar solution. The identity of the individuals was confirmed using the morphological keys of Rueda [28]. 


\subsection{Bright Field and Fluorescence Microscopy}

Individual mosquitoes were cold anesthetized and transferred to a cover slip to allow microscopic observation. The heads were dissected from cold anesthetized adults and submitted to a similar mounting procedure. Autofluorescence images were acquired by means of an Olympus BX53 fluorescence microscope (Olympus Optical Co. GmbH, Hamburg, Germany), equipped with an X-Cite 120 Q illumination system (120 W Hg vapor short arc lamp) as the fluorescence excitation source, and the UFUW optical cube for light selection (340-390 nm excitation filter, $410 \mathrm{~nm}$ dichromatic mirror, $420 \mathrm{~nm}$ long pass filter). Images were recorded using an EOS 1300D Olympus camera, by means of the Olympus objectives Plan $4 \times(0.10)$, UPlanFL $10 \times(0.30)$, UPlanFL $20 \times(0.50)$, and UPlanFL $40 \times(0.75)$. Pictures were optimized with the IrfanView 4.54 program (Irfan Skiljan copyright 1996-2020), and figure plates realized with Adobe Illustrator CC 2017 v. 21.0.0.

\subsection{Spectrofluorimetric Analysis}

Autofluorescence emission spectra were recorded from the samples under epi-illumination by means of a microspectrograph (Leitz, Wetzlar, Germany), equipped with a 100W/Hg excitation lamp (Osram, Berlin, Germany), combined with KG1-BG38 anti-thermal filters. A $366 \mathrm{~nm}$ band-pass interference excitation filter (FWHM $10 \mathrm{~nm}$ ) was used to select the excitation light; fluorescence signals were recorded through a 50/50 dichroic mirror and a $390 \mathrm{~nm}$ long pass filter, using a $40 \times$ objective. Fluorescence emission signals were guided to a Hamamatzu PMA-12 photonic multichannel analyzer (Hamamatsu Photonics Italia Srl, Arese, Italy) by means of a fiber optic probe optically coupled to the exit slitof the microspectrograph. Spectra were recorded in the 400-750 nm interval, stored on magnetic mass memory and processed using Microsoft Excel for normalization to the maximum peak value and presentation.

\section{Conclusions}

In this study we provide, for the first time, a description of the AF patterns in Ae. albopictus head appendages and body scales. Our spectral data identified a number of fluorophore candidates that will be further explored through adoption of an interdisciplinary approach involving biological, physical and chemical methods. Further investigation on mosquito AF, and the chemical composition of its underlying biomolecules, is expected to improve our knowledge of insect metabolism, and of its implications in ecology and behavior. In this regard, AF patterns have demonstrated the potential to provide additional information on sexually dimorphic body compartments in Ae. albopictus, particularly the antennae, and can help to achieve further understanding of mating behavior and host-seeking.

Expanding knowledge on mosquito optical properties can also provide new tools for their tracing, for example contributing to develop in-flight detection and surveillance of vectors [7]. Moreover, these results pave the way to further investigation of natural fluorescence as an inter- and intra-specific communication signal and will clarify whether $\mathrm{AF}$ in Ae. albopictus may be an adaptive trait, for example, in helping to reduce detection by predators through camouflage.

Supplementary Materials: The following is available online: Figure S1: Showing microscope images and emission spectra from a fore trochanter-femur joint and a portion of a maxilla, as typical examples of structures enriched with bluish fluorescing resilin and reddish fluorescing sclerotized chitin, respectively.

Author Contributions: A.C.C. and F.S. equally participated in: conceptualization, methodology and analysis, writing, review and editing, figures' preparation. All authors have read and agreed to the published version of the manuscript.

Funding: This research received no external funding.

Institutional Review Board Statement: Not applicable.

Informed Consent Statement: Not applicable. 


\section{Data Availability Statement: Not applicable.}

Acknowledgments: The photograph of Aedes albopictus used in the graphical abstract is a modified version of the original picture: ECDC 21-6183 access request, 6 December 2021. The key is based on illustrations made by Disa Eklöf and photos by Anders Lindström from the National Veterinary Institute/SVA. Anders Lindström owns the copyright of all photographs and Disa Eklöf owns the copyright of all illustrations. An icon created with BioRender.com was integrated in the graphical abstract.

Conflicts of Interest: The authors declare no conflict of interest.

Sample Availability: Mosquito samples are not available from the authors, because procured from the wild and analyzed as fresh material, to prevent time dependent alterations.

\section{References}

1. Udenfriend, S. Fluorescence Assay in Biology and Medicine, 1st ed.; Horecker, B., Kaplan, N.O., Marmur, J., Scheraga, H.A., Eds.; Academic Press: New York, NY, USA; London, UK, 1969; Volume 2, pp. 195-404.

2. Croce, A.C. Light and autofluorescence, multitasking features in living organisms. Photochem 2021, 1, 67-125. [CrossRef]

3. Lagorio, M.G.; Cordon, G.B.; Iriel, A. Reviewing the relevance of fluorescence in biological systems. Photochem. Photobiol. Sci. 2015, 14, 1538-1559. [CrossRef] [PubMed]

4. Marshall, J.; Johnsen, S. Fluorescence as a means of colour signal enhancement. Philos. Trans. R. Soc. B Biol. Sci. 2017, 372. [CrossRef] [PubMed]

5. Abels, J.P.; Ludescher, R.D. Native fluorescence from juvenile stages of common food storage insects. J. Agric. Food Chem. 2003, 51, 544-549. [CrossRef]

6. Rosales, A.C.; Atencio, J.A.D.; Rodríguez, M.C.; Gutiérrez, E.G. In-vivo measurement of the fluorescence spectrum of wild cochineal (Dactylopius opuntiae). Sci. Rep. 2021, 11, 446. [CrossRef] [PubMed]

7. Gebru, A.; Jansson, S.; Ignell, R.; Kirkeby, C.; Prangsma, J.C.; Brydegaard, M. Multiband modulation spectroscopy for the determination of sex and species of mosquitoes in flight. J. Biophotonics 2018, 11. [CrossRef]

8. Cockayne, E.A.I. The distribution of fluorescent pigments in Lepidoptera. Trans. R. Entomol. Soc. Lond. 1924, 72, 1-19. [CrossRef]

9. Wilts, B.D.; Trzeciak, T.M.; Vukusic, P.; Stavenga, D.G. Papiliochrome II pigment reduces the angle dependency of structural wing colouration in nireus group papilionids. J. Exp. Biol. 2012, 215, 796-805. [CrossRef]

10. Wilts, B.D.; Ijbema, N.; Stavenga, D.G. Pigmentary and photonic coloration mechanisms reveal taxonomic relationships of the Cattlehearts (Lepidoptera: Papilionidae: Parides). BMC Evol. Biol. 2014, 14, 160. [CrossRef]

11. Vigneron, J.P.; Kertész, K.; Vértesy, Z.; Rassart, M.; Lousse, V.; Bálint, Z.; Biró, L.P. Correlated diffraction and fluorescence in the backscattering iridescence of the male butterfly Troides magellanus (Papilionidae). Phys. Rev. E Stat. Nonlin. Soft Matter. Phys. 2008, 78 [CrossRef]

12. Mouchet, S.R.; Tabarrant, T.; Lucas, S.; Su, B.-L.; Vukusic, P.; Deparis, O. Vapor sensing with a natural photonic cell. Opt. Express 2016, 24, 12267. [CrossRef] [PubMed]

13. Michels, J.; Appel, E.; Gorb, S.N. Functional diversity of resilin in Arthropoda. Beilstein J. Nanotechnol. 2016, 7, 1241-1259. [CrossRef] [PubMed]

14. Bäumler, F.; Büsse, S. Resilin in the flight apparatus of Odonata (Insecta) cap tendons and their biomechanical importance for flight. Biol. Lett. 2019, 15. [CrossRef] [PubMed]

15. Pentzold, S.; Marion-Poll, F.; Grabe, V.; Burse, A. Autofluorescence-based identification and functional validation of antennal gustatory sensilla in a specialist leaf beetle. Front. Physiol. 2019, 10, 343. [CrossRef]

16. Saltin, B.D.; Matsumura, Y.; Reid, A.; Windmill, J.F.; Gorb, S.N.; Jackson, J.C. Resilin distribution and sexual dimorphism in the midge antenna and their influence on frequency sensitivity. Insects 2020, 11, 520. [CrossRef]

17. Saltin, B.D.; Matsumura, Y.; Reid, A.; Windmill, J.F.; Gorb, S.N.; Jackson, J.C. Material stiffness variation in mosquito antennae. J. R. Soc. Interface 2019, 16. [CrossRef]

18. Paupy, C.; Delatte, H.; Bagny, L.; Corbel, V.; Fontenille, D. Aedes albopictus, an arbovirus vector: From the darkness to the light. Microbes Infect. 2009, 11, 1177-1185. [CrossRef]

19. Wong, P.S.J.; Li, M.; Zhi, I.; Chong, C.S.; Ng, L.C.; Tan, C.H. Aedes (Stegomyia) albopictus (Skuse): A potential vector of Zika virus in Singapore. PLoS Negl. Trop. Dis. 2013, 7, e2348. [CrossRef]

20. Vega-Rúa, A.; Marconcini, M.; Madec, Y.; Manni, M.; Carraretto, D.; Gomulski, L.M.; Gasperi, G.; Failloux, A.B.; Malacrida, A.R. Vector competence of Aedes albopictus populations for Chikungunya virus is shaped by their demographic history. Commun. Biol. 2020, 3, 1-13. [CrossRef]

21. Chouin-Carneiro, T.; Vega-Rua, A.; Vazeille, M.; Yebakima, A.; Girod, R.; Goindin, D.; Dupont-Rouzeyrol, M.; Lourenço-deOliveira, R.; Failloux, A.B. Differential susceptibilities of Aedes aegypti and Aedes albopictus from the Americas to Zika virus. PLoS Negl. Trop. Dis. 2016, 10, e0004543. [CrossRef]

22. Grard, G.; Caron, M.; Mombo, I.M.; Nkoghe, D.; Mboui Ondo, S.; Jiolle, D.; Fontenille, D.; Paupy, C.; Leroy, E.M. Zika virus in Gabon (Central Africa) 2007: A new threat from Aedes albopictus? PLoS Negl. Trop. Dis. 2014, 8, e2681. [CrossRef] [PubMed] 
23. Jupille, H.; Seixas, G.; Mousson, L.; Sousa, C.A.; Failloux, A.B. Zika virus, a new threat for Europe? PLoS Negl. Trop. Dis. 2016, 10, e0004901. [CrossRef] [PubMed]

24. Armstrong, P.M.; Ehrlich, H.Y.; Magalhaes, T.; Miller, M.R.; Conway, P.J.; Bransfield, A.; Misencik, M.J.; Gloria-Soria, A.; Warren, J.L.; Andreadis, T.G.; et al. Successive blood meals enhance virus dissemination within mosquitoes and increase transmission potential. Nat. Microbiol. 2020, 5, 239-247. [CrossRef] [PubMed]

25. Wilke, A.B.B.; Benelli, G.; Beier, J.C. Beyond frontiers: On invasive alien mosquito species in America and Europe. PLoS Negl. Trop. Dis. 2020, 14, e0007864. [CrossRef] [PubMed]

26. Nansen, C. Penetration and scattering two optical phenomena to consider when applying proximal remote sensing technologies to object classifications. PLoS ONE 2019, 13, e0204579. [CrossRef] [PubMed]

27. Klowden, M.J. Blood, sex, and the mosquito. BioScience 1995, 45, 326-331. [CrossRef]

28. Rueda, L.M. Pictorial keys for the identification of mosquitoes (Diptera: Culicidae) associated with Dengue virus transmission Zootaxa 2004, 589, 1-60. [CrossRef]

29. Huang, Y.-M. Neotype designation for Aedes (Stegomyia) albopictus (Skuse) (Diptera: Culicidae). Proc. Entomol. Soc. Wash 1968, 70, 297-302.

30. McIver, S. Comparative studies on the sense organs on the antennae and maxillary palps of selected male culicine mosquitoes. Can. J. Zool. 1971, 49, 235-239. [CrossRef]

31. Hawley, W.A. The biology of Aedes albopictus. J. Am. Mosq. Control. Assoc. Suppl. 1988, 1, 1-39.

32. Cerkvenik, U.; Dodou, D.; van Leeuwen, J.L.; Gussekloo, S.W.S. Functional principles of steerable multi-element probes in insects. Biol. Rev. Camb. Philos. Soc. 2019, 94, 555-574. [CrossRef] [PubMed]

33. Muthukrishnan, S.; Merzendorfer, H.; Arakane, Y.; Kramer, K.J. Chitin metabolism in insects. Insect Mol. Biol. Biochem. 2012, 193-235.

34. Neff, D.; Frazier, S.F.; Quimby, L.; Wang, R.T.; Zill, S. Identification of resilin in the leg of cockroach, Periplaneta americana: Confirmation by a simple method using pH dependence of UV fluorescence. Arthropod Struct. Dev. 2000, 29, 75-83. [CrossRef]

35. Gorb, S.N. Design of insect unguitractor apparatus. J. Morphol. 1996, 230, 219-230. [CrossRef]

36. Chang, M.P.; Huang, W.; Mai, D.J. Monomer-scale design of functional protein polymers using consensus repeat sequences. J. Polym. Sci. 2021, 59, 2644-2664. [CrossRef]

37. Andersen, S. Structure and function of resilin. In Elastomeric Proteins: Structures, Biomechanical Properties, and Biological Roles, Shewry, P., Tatham, A., Bailey, A., Eds.; Cambridge University Press: Cambridge, UK, 2003; pp. 259-278.

38. Gorb, S.N. Serial elastic elements in the damselfly wing: Mobile vein joints contain resilin. Naturwissenschaften 1999, 86, $552-555$. [CrossRef]

39. He, N.; Botelho, J.M.C.; McNall, R.J.; Belozerov, V.; Dunn, W.A.; Mize, T.; Orlando, R.; Willis, J.H. Proteomic analysis of cast cuticles from Anopheles gambiae by tandem mass spectrometry. Insect Biochem. Mol. Biol. 2007, 37, 135-146. [CrossRef]

40. Ramasamy, R.; Thiruchenthooran, V.; Jayadas, T.T.P.; Eswaramohan, T.; Santhirasegaram, S.; Sivabalakrishnan, K.; Naguleswaran, A.; Uzest, M.; Cayrol, B.; Voisin, S.N.; et al. Transcriptomic, proteomic and ultrastructural studies on salinity-tolerant Aedes aegypti in the context of rising sea levels and arboviral disease epidemiology. BMC Genom. 2021, 22, 253. [CrossRef]

41. Curtin, T.J.; Jones, J.C. The mechanism of ovulation and oviposition in Aedes aegypti. Ann. Entomol. Soc. Am. 1961, 54, 298-313. [CrossRef]

42. Clements, A.N.; Potter, S.A. The fine structure of the spermathecae and their ducts in the mosquito Aedes aegypti. J. Insect Physiol. 1967, 13, 1825-1836. [CrossRef]

43. Pascini, T.V.; Ramalho-Ortigão, M.; Martins, G.F. Morphological and morphometrical assessment of spermathecae of Aedes aegypti females. Mem. Inst. Oswaldo Cruz 2012, 107, 705-712. [CrossRef] [PubMed]

44. Giglioli, M.E. The female reproductive system of Anopheles gambiae melas. The structure and function of the genital ducts and associated organs. Riv. Malariol. 1963, 42, 149-176.

45. Lee, R.M.K.W.; Craig, D.A. The labrum and labral sensilla of mosquitoes (Diptera: Culicidae): A scanning electron microscope study. Can. J. Zool. 1983, 61, 1568-1579. [CrossRef]

46. Scolari, F.; IGM-CNR, Pavia, Italy. Personal Communication, 2021.

47. Nuttall, G.H.F.; Shipley, A.E. Studies in relation to malaria: II. The structure and biology of Anopheles. J. Hyg. 1901, 1, 451-484 [CrossRef] [PubMed]

48. Kaya, M.; Bulut, E.; Mujtaba, M.; Sivickis, K.; Sargin, I.; Akyuz, B.; Erdogan, S. Gender influences differentiation of chitin among body parts. Arch. Insect Biochem. Physiol. 2016, 93, 96-109. [CrossRef]

49. Tauber, O.E. The distribution of chitin in an insect. J. Morphol. 1934, 56, 51-58. [CrossRef]

50. Qin, G.; Hu, X.; Cebe, P.; Kaplan, D.L. Mechanism of resilin elasticity. Nat. Commun. 2012, 3, 1-9. [CrossRef]

51. Qin, G.; Lapidot, S.; Numata, K.; Hu, X.; Meirovitch, S.; Dekel, M.; Podoler, I.; Shoseyov, O.; Kaplan, D.L. Expression, cross-linking, and characterization of recombinant chitin binding resilin. Biomacromolecules 2009, 10, 3227-3234. [CrossRef]

52. Appel, E.; Heepe, L.; Lin, C.P.; Gorb, S.N. Ultrastructure of dragonfly wing veins: Composite structure of fibrous material supplemented by resilin. J. Anat. 2015, 227, 561-582. [CrossRef]

53. Hou, J.; Aydemir, B.E.; Dumanli, A.G. Understanding the structural diversity of chitins as a versatile biomaterial. Philos. Trans. A Math. Phys. Eng. Sci. 2021, 379, 1-19. [CrossRef] 
54. Liu, X.; Zhang, J.; Zhu, K.Y. Chitin in arthropods: Biosynthesis, modification, and metabolism. Adv. Exp. Med. Biol. 2019, 1142, 169-207. [PubMed]

55. Rabasović, M.D.; Pantelić, D.V.; Jelenković, B.M.; Ćurčić, S.B.; Rabasović, M.S.; Vrbica, M.D.; Lazović, V.M.; Ćurčić, B.P.M.; Krmpot, A.J. Nonlinear microscopy of chitin and chitinous structures: A case study of two cave-dwelling insects. J. Biomed. Opt. 2015, 20, 1. [CrossRef] [PubMed]

56. Michels, J.; Gorb, S.N. Detailed three-dimensional visualization of resilin in the exoskeleton of arthropods using confocal laser scanning microscopy. J. Microsc. 2012, 245, 1-16. [CrossRef] [PubMed]

57. Peisker, H.; Michels, J.; Gorb, S.N. Evidence for a material gradient in the adhesive tarsal setae of the ladybird beetle Coccinella septempunctata. Nat. Commun. 2013, 4, 1661. [CrossRef]

58. Göpfert, M.C.; Briegel, H.; Robert, D. Mosquito hearing: Sound-induced antennal vibrations in male and female Aedes aegypti. J. Exp. Biol. 1999, 202, 2727-2738. [CrossRef]

59. Robert, D. Insect bioacoustics: Mosquitoes make an effort to listen to each other. Curr. Biol. 2009, 19, R446-R449. [CrossRef]

60. Gibson, G.; Russell, I. Flying in tune: Sexual recognition in mosquitoes. Curr. Biol. 2006, 16, 1311-1316. [CrossRef]

61. Lu, T.; Qiu, Y.T.; Wang, G.; Kwon, J.Y.; Rutzler, M.; Kwon, H.W.; Pitts, R.J.; van Loon, J.J.A.; Takken, W.; Carlson, J.R.; et al. Odor coding in the maxillary palp of the malaria vector mosquito Anopheles gambiae. Curr. Biol. 2007, 17, 1533-1544. [CrossRef]

62. McIver, S.; Charlton, C. Studies on the sense organs on the palps of selected culicine mosquitoes. Can. J. Zool. 1970, 48, 293-295. [CrossRef]

63. Bohbot, J.D.; Sparks, J.T.; Dickens, J.C. The maxillary palp of Aedes aegypti, a model of multisensory integration. Insect Biochem. Mol. Biol. 2014, 48, 29-39. [CrossRef]

64. Grant, A.J.; Wigton, B.E.; Aghajanian, J.G.; O'Connell, R.J. Electrophysiological responses of receptor neurons in mosquito maxillary palp sensilla to carbon dioxide. J. Comp. Physiol. A 1995, 177, 389e396. [CrossRef] [PubMed]

65. Thom, C.; Guerenstein, P.G.; Mechaber, W.L.; Hildebrand, J.G. Floral $\mathrm{CO}_{2}$ reveals flower profitability to moths. J. Chem. Ecol. 2004, 30, 1285-1288. [CrossRef] [PubMed]

66. Athrey, G.; Popkin-Hall, Z.R.; Takken, W.; Slotman, M.A. The expression of chemosensory genes in male maxillary palps of Anopheles coluzzii (Diptera: Culicidae) and An. quadriannulatus. J. Med. Entomol. 2021, 58, 1012-1020. [CrossRef] [PubMed]

67. Wang, Q.; Shang, Y.; Hilton, D.S.; Inthavong, K.; Zhang, D.; Elgar, M.A. Antennal scales improve signal detection efficiency in moths. Proc. Biol. Sci. 2018, 285, 20172832. [CrossRef] [PubMed]

68. Clements, A.N. The Biology of Mosquitoes: Development, Nutrition and Reproduction; Chapman \& Hall: London, UK, 1992; Volume 1, p. 532.

69. Neil, T.R.; Shen, Z.; Robert, D.; Drinkwater, B.W.; Holderied, M.W. Moth wings are acoustic metamaterials. Proc. Natl. Acad. Sci. USA 2020, 117, 31134-31141. [CrossRef]

70. Ito, K.; Yoshikawa, M.; Fujii, T.; Tabunoki, H.; Yokoyama, T. Melanin pigmentation gives rise to black spots on the wings of the silkworm Bombyx mori. J. Insect Physiol. 2016, 91-92, 100-106. [CrossRef]

71. Matsuoka, Y.; Monteiro, A. Melanin pathway genes regulate color and morphology of butterfly wing scales. Cell Rep. 2018, 24, 56-65. [CrossRef]

72. Whitten, M.M.A.; Coates, C.J. Re-evaluation of insect melanogenesis research: Views from the dark side. Pigment. Cell Melanoma Res. 2017, 30, 386-401. [CrossRef]

73. Kuwalekar, M.; Deshmukh, R.; Padvi, A.; Kunte, K. Molecular evolution and developmental expression of melanin pathway genes in Lepidoptera. Front. Ecol. Evol. 2020, 8, 226. [CrossRef]

74. Mostert, A.B. Melanin, the what, the why and the how: An introductory review for materials scientists interested in flexible and versatile polymers. Polymers 2021, 13, 1670. [CrossRef]

75. Stavenga, D.G.; Leertouwer, H.L.; Hariyama, T.; de Raedt, H.A.; Wilts, B.D. Sexual dichromatism of the damselfly Calopteryx japonica caused by a melanin-chitin multilayer in the male wing veins. PLoS ONE 2012, 7, e49743. [CrossRef] [PubMed]

76. Meredith, P.; Sarna, T. The physical and chemical properties of eumelanin. Pigment Cell Res. 2006, 19, 572-594. [CrossRef] [PubMed]

77. Meredith, P.; Powell, B.J.; Riesz, J.; Nighswander-Rempel, S.P.; Pederson, M.R.; Moore, E.G. Towards structure-property-function relationships for eumelanin. Soft Matter. 2006, 2, 37-44. [CrossRef] [PubMed]

78. El Nahhas, A.; Pascher, T.; Leone, L.; Panzella, L.; Napolitano, A.; Sundström, V. Photochemistry of pheomelanin building blocks and model chromophores: Excited-state intra- and intermolecular proton transfer. J. Phys. Chem. Lett. 2014, 5, 2094-2100. [CrossRef]

79. Djokic, S.; Bakhrat, A.; Tsurim, I.; Urakova, N.; Rasgon, J.L.; Abdu, U. Actin bundles play a different role in shaping scales compared to bristles in the mosquito Aedes aegypti. Sci. Rep. 2020, 10, 14885. [CrossRef]

80. Winterton, S.L. Chapter 229 Scales and Setae. In Encyclopedia of Insects, 2nd ed.; Resh, V.H., Cardé, R.T., Eds.; Academic Press (Elsevier): Burlington, MA, USA, 2009; pp. 901-904.

81. Tsuda, Y.; Yotopranoto, S.; Bendryman, S.S.; Rosmanida Dachlan, Y.P.; Takagi, M. Seasonal changes in variation of dorsal scale pattern of Aedes aegypti (L.) (Diptera: Culicidae) in Surabaya, Indonesia. Med. Entomol. Zool. 2003, 54, 73-80. [CrossRef]

82. Theobald, F.V. Genera insectorum, Diptera. Fam. Culicidae; L. Desmet-Verteneuil: Brussels, Belgium, 1905; Volume 26, pp. 1-50.

83. Theobald, F.V. The classification of mosquitoes. J. Trop. Med. 1901, 4, 229-235. 
84. Ong, S.Q.; Ahmad, H.; Nair, G.; Isawasan, P.; Majid, A.H.A. Implementation of a deep learning model for automated classification of Aedes aegypti (Linnaeus) and Aedes slbopictus (Skuse) in Real Time. Sci. Rep. 2021, 11, 1-12. [CrossRef]

85. Verna, T.N.; Munstermann, L.E. Morphological variants of Aedes aegypti collected from the Leeward Island of Antigua. J. Am. Mosq. Control Assoc. 2011, 27, 308-311. [CrossRef] 